\title{
Mineralogia, química e estabilidade de agregados do tamanho de silte de solos da Região Sudeste do Brasil(1)
}

\author{
Antonio Carlos Tadeu Vitorino(2), Mozart Martins Ferreira ${ }^{(3)}$, Nilton Curi(3) , José Maria de Lima ${ }^{(3)}$, \\ Marx Leandro Naves Silva ${ }^{(3)}$ e Paulo Emílio Ferreira da Motta ${ }^{(4)}$
}

\begin{abstract}
Resumo - Com o objetivo de avaliar a relação da composição mineralógica e química do solo com a estabilidade de agregados do tamanho de silte, foram realizados estudos utilizando-se amostras de horizontes A e B de diversos solos da Região Sudeste do Brasil. Amostras de TFSA foram dispersas a $12.000 \mathrm{rpm}$ por 20 minutos e a fração silte foi separada por esgotamento da fração argila, constituindose na fração denominada pseudo-silte, a qual foi sonificada, separando-se a fração argila desagregada (por sifonamento) da fração silte propriamente dita. Estudos de correlação mostraram que as composições mineralógica e química dos solos têm efeito marcante na dispersão de argila, com reflexos na fração silte. Maiores teores de gibbsita refletem em maior estabilidade dos agregados do tamanho de silte ao passo que a caulinita proporciona efeito inverso. As formas de $\mathrm{Al}$ determinadas na fração pseudo-silte estão associadas à maior dificuldade de dispersão da fração argila dos solos.
\end{abstract}

Termos para indexação: composição química, mineral, argila, dispersão.

\section{Mineralogy, chemistry and stability of silt-size aggregates of soils from the Southeast Region of Brazil}

\begin{abstract}
The objective of this work was to evaluate the relationship of soil mineralogical and chemical composition with stability of silt-size aggregates. The studies were carried out using samples of A and B horizons of some soils from the Southeast Region of Brazil. Fine-earth samples were dispersed at $12,000 \mathrm{rpm}$ during 20 minutes and the silt fraction was separated through clay fraction drain, constituting the fraction named pseudo-silt, which was sonificated, separating the desegregated clay fraction (by sonication) from the properly named silt fraction. Correlation analyses showed that the soil mineralogical and chemical compositions have marked influence upon clay dispersion, with reflections on the silt fraction. Higher amounts of gibbsite reflect in higher stability of silt-size aggregates, while the kaolinite promotes inverse effect. The $\mathrm{Al}$ forms determined on the pseudo-silt fraction are associated with higher difficult of dispersion of clay fraction of soils.
\end{abstract}

Index terms: chemical composition, mineral, clay, dispersion.

\section{Introdução}

Análises granulométricas de alguns solos brasileiros têm apresentado com certa frequiência resultados superestimados dos teores de silte, incompatíveis com o grau de intemperismo dos solos.

(1) Aceito para publicação em 25 de setembro de 2002 .

(2) Universidade Federal de Mato Grosso do Sul, Dep. de Ciências Agrárias, Caixa Postal 533, CEP 79804-907 Dourados, MS. E-mail: vitorino@ceud.ufms.br

(3) Universidade Federal de Lavras, Dep. de Ciência do Solo, Caixa Postal 37, CEP 37200-000 Lavras, MG. E-mail:mozartmf@ufla.br, niltcuri@ufla.br,jmlima@ufla.br, marx@ufla.br

(4) Embrapa-Centro Nacional de Pesquisa de Solos, Rua Jardim Botânico, 1024, CEP 22460-000 Rio de Janeiro, RJ E-mail: motta@cnps.embrapa.br
Na realidade, parte desse silte é composto por agregados de argila formados pela ação de agentes cimentantes, e, segundo alguns autores, o fenômeno torna-se mais acentuado nos solos mais oxídicos (Santana, 1973; Kunze \& Dixon, 1986).

Moura Filho \& Buol (1972) constataram que os Latossolos com maior grau de intemperismo apresentam microagregados resistentes à dispersão, corroborando relatos de Ferreira et al. (1999b), de que Latossolos gibbsíticos desenvolvem estrutura granular muito estável. Da mesma forma, Netto (1996) observou em diferentes Latossolos que o índice $\mathrm{Kr}$ correlacionou-se negativamente com o teor de silte, sugerindo que, em solos mais intemperizados, com maiores teores de óxidos de $\mathrm{Fe}$ e de $\mathrm{Al}$, a fração silte seria incrementada pela presença de microagregados 
de argila. Também a importância das formas de Al associadas à matéria orgânica com a agregação dos solos é enfatizada por Pedrotti (2000). A dificuldade de se dispersar a argila contida em agregados na fração silte de alguns solos, pode, então, ser relacionada tanto com a presença de agentes cimentantes como também com a pouca eficiência dos procedimentos rotineiramente adotados para tal execução.

A dispersão adequada da amostra de solo tem sido, portanto, um fator limitante na obtenção das frações texturais em alguns Latossolos, com altos teores de óxidos de Fe e de Al (Donagemma, 2000).

Estudos mais detalhados sobre a constituição mineralógica e química dos constituintes dessa fração podem contribuir significativamente para a obtenção de melhores resultados de análises laboratoriais para determinar a granulometria do solo, bem como ajudar no entendimento da participação do "silte funcional" como importante componente físico em fenômenos como selamento superficial e erosão.

O objetivo deste trabalho foi avaliar as influências da composição mineralógica e química do solo na dispersão da fração argila e na estabilidade dos agregados do tamanho de silte.

\section{Material e Métodos}

As amostras selecionadas foram coletadas sob condições naturais de horizontes A e B dos seguintes solos: Latossolo Amarelo coeso (LAx), Latossolo VermelhoAmarelo distrófico (LVAd), Latossolo Vermelho distrófico (LVd), Latossolo Vermelho distroférrico (LVdf), Argissolo Amarelo distrófico (PAd), Argissolo Vermelho-Amarelo distrófico (PVAd), Argissolo Vermelho distrófico (PVd), Nitossolo Vermelho distrófico (NVd), Cambissolo Háplico Tb distrófico originado de filito (CXbd1) e Cambissolo Háplico $\mathrm{Tb}$ distrófico originado de gnaisse (CXbd2), todos apresentando horizonte A moderado e atributos morfológicos típicos das respectivas classes. O LAx e o PAd são provenientes dos municípios de Aracruz, ES (clima Aw), e de Campos dos Goytacazes, RJ (clima Aw), respectivamente; o LVd, da zona fisiográfica Campos das Vertentes, MG (clima Cwa); e os demais, do Sul de Minas (clima Cwb).

$\mathrm{Na}$ caracterização da dificuldade de dispersão da fração argila dos solos, foram realizadas análises granulométricas pelo método da pipeta em amostras de TFSA dos horizontes A e B dos solos (Embrapa, 1997), usando
$\mathrm{NaOH} 1 \mathrm{~mol} \mathrm{~L}^{-1}$ como dispersante químico e adotando-se dois procedimentos mecânicos de dispersão. No primeiro, a dispersão foi realizada com agitação a $12.000 \mathrm{rpm}$ por 20 minutos. No segundo, a dispersão foi realizada com sonificação em aparelho marca Misonix, modelo XL2020 $0^{\mathrm{TM}}$, operando no estágio quatro, fornecendo uma potência nominal de 27,5 W calculada conforme Sá (2000) e seguindo relação solo:solução e tempo de sonificação suficientes para fornecer a energia equivalente a $110 \mathrm{~J} \mathrm{~mL}^{-1}$, conforme Vitorino et al. (2001). Registrou-se diferença nos teores de argila obtidos nos dois procedimentos analíticos adotados.

Na caracterização da fração silte, amostras de TFSA dos horizontes A e B dos solos foram submetidas ao processo de dispersão por agitação rápida, seguindo os métodos anteriormente descritos. Após a separação da fração areia em peneira de $0,053 \mathrm{~mm}$, a suspensão foi homogeneizada e permaneceu em repouso por tempo suficiente para a retirada da argila por sifonamento, segundo a lei de Stokes. O pH da suspensão foi mantido acima do ponto de efeito salino nulo (PESN) das amostras para evitar floculação das argilas em suspensão. Esse procedimento foi repetido até que a suspensão se tornasse límpida, sugerindo o esgotamento da fração argila. O silte sedimentado foi separado, congelado e liofilizado, para ser submetido a futuros procedimentos analíticos. A fração silte obtida foi denominada pseudo-silte, pela possibilidade de conter agregados de partículas de argila.

O pseudo-silte foi submetido a novo processo de dispersão utilizando-se $\mathrm{NaOH} 1 \mathrm{~mol} \mathrm{~L}^{-1}$ como dispersante químico e a sonificação para a dispersão mecânica das amostras. A suspensão transferida para provetas de $2 \mathrm{~L}$ foi homogeneizada e teve a fração argila (argila desagregada) esgotada por sifonamento. O material recolhido no fundo das provetas foi congelado e liofilizado, constituindo-se na fração silte.

Análises mineralógicas das frações pseudo-silte, silte e argila desagregada foram realizadas por meio de difração de raios X (DRX) de lâminas não orientadas em difratômetro Phillips PW1840, equipado com tubo de cobalto (Co) e filtro de ferro, em voltagem de $35 \mathrm{kV}$ e corrente de $25 \mathrm{~mA}$, e irradiação realizada no intervalo de 5 a $32^{\circ} 2 \theta$. A velocidade de varredura da amostra no difratômetro foi de $0,02^{\circ} 2 \theta / \mathrm{s}$, com espaçamento entre leitura de $0,02^{\circ} 2 \theta$ e tempo de leitura em cada passo de 2,5 segundos.

Amostras das frações pseudo-silte, silte e argila desagregada desferrificadas foram submetidas à análise térmica diferencial (ATD), e quantificados os teores de caulinita e gibbsita. Ferro $\left(\mathrm{Fe}_{\mathrm{d}}\right)$ e alumínio $\left(\mathrm{Al}_{\mathrm{d}}\right)$ foram extraídos com ditionito-citrato-bicarbonato de sódio (DCB) de acordo com Mehra \& Jackson (1960). As formas de 
ferro $\left(\mathrm{Fe}_{\mathrm{o}}\right)$ e alumínio $\left(\mathrm{Al}_{\mathrm{o}}\right)$ de baixo grau de cristalinidade foram extraídas com solução de oxalato ácido de amônio, conforme Schwertmann (1964). O ferro $\left(\mathrm{Fe}_{\mathrm{p}}\right)$ e o alumínio $\left(\mathrm{Al}_{\mathrm{p}}\right)$, ligados à fração orgânica, foram extraídos com pirofosfato de sódio $0,1 \mathrm{~mol} \mathrm{~L}^{-1}$, segundo McKeague (1967). Todas as determinações de Fe e Al foram feitas por espectrofotometria de absorção atômica, com três repetições. Os dados obtidos foram tratados estatisticamente por análises de variância, testes de médias e correlações.

\section{Resultados e Discussão}

O método que envolveu o uso de energia ultrasônica para a dispersão da TFSA proporcionou teores de argila, na maioria dos casos, significativamente iguais ou superiores ao método que empregou a agitação rápida, tanto nas amostras de horizontes A como B dos solos estudados (Tabela 1). Esses resultados podem ser atribuídos à maior eficiência da energia ultra-sônica em promover a quebra de agregados do tamanho de silte e areia, transformando-os em partículas individualizadas do tamanho de argila. Estudos mostrando a maior eficiência da energia ultrasônica na dispersão de argila foram apresentados por Edwards \& Bremner (1967); Saly (1967); Genrich \& Bremner (1972) e Gregorich et al. (1988).

Os difratogramas das frações silte e pseudo-silte dos horizontes A e B mostram que, entre os Latossolos, os solos LAx e LVd apresentam a mineralogia mais contrastante no que diz respeito aos teores de caulinita e gibbsita (Figuras 1 e 2). No LAx, solo de composição essencialmente caulinítica, ob- serva-se pequeno reflexo de caulinita na fração pseudo-silte, que tende a diminuir substancialmente após a sonificação, com conseqüente aumento relativo de intensidade do reflexo de quartzo na fração silte (Figura 1). O LVd, de mineralogia mais gibbsítica (Figura 2), apresenta reflexos de caulinita e de gibbsita na fração pseudo-silte, que permanecem mesmo após a sonificação na fração silte, indicando, além da presença desses minerais como constituintes desses agregados, maior dificuldade de individualização das partículas desse solo durante a dispersão.

O processo de separação da fração silte permitiu visualizar que o quartzo é o mineral predominante nessa fração. Embora gibbsita e caulinita possam ocorrer na fração silte, a presença desses minerais, como evidenciado nos difratogramas, pode também indicar que o nível de energia utilizado no processo de separação não foi suficiente para a remoção completa desses minerais. No caso específico do LAx (Figura 1) e dos outros solos de constituição essencialmente caulinítica estudados (Tabela 2), o pico de caulinita desaparece após a sonificação do pseudosilte e retirada da argila. A permanência dos picos de gibbsita nos difratogramas do silte dos demais solos reforça o papel desse mineral na maior resistência que os agregados oferecem à dispersão, fato também comentado por Netto (1996). Silva et al. (1998), Ferreira et al. (1999a) e Resende et al. (1999) também relatam que a presença da gibbsita ajuda a manter a estrutura microgranular.

Tabela 1. Teores de argila $\left(\mathrm{g} \mathrm{kg}^{-1}\right)$ da terra fina seca ao ar (TFSA) nos horizontes Ae B de amostras de diferentes solos, determinados por procedimentos químico-mecânico de dispersão (DQM), químico-mecânico seguido de sonificação $(\mathrm{DQM}+\mathrm{S})$ e diferença entre os teores de argila obtidos por esses procedimentos ${ }^{(1)}$.

\begin{tabular}{lcccccccccc}
\hline Dispersão & LAx & LVAd & LVd & LVdf & PAd & PVAd & PVd & NVd & CXbd1 & CXbd2 \\
\hline & & & & \multicolumn{7}{c}{ Horizonte A } \\
DQM+S & $265,5 \mathrm{a}$ & $384,8 \mathrm{a}$ & $776,7 \mathrm{a}$ & $794,2 \mathrm{a}$ & $173,6 \mathrm{a}$ & $433,3 \mathrm{a}$ & $319,8 \mathrm{a}$ & $301,5 \mathrm{a}$ & $615,1 \mathrm{a}$ & $450,0 \mathrm{a}$ \\
DQM & $273,7 \mathrm{a}$ & $325,5 \mathrm{~b}$ & $557,3 \mathrm{~b}$ & $743,7 \mathrm{~b}$ & $169,8 \mathrm{a}$ & $379,4 \mathrm{~b}$ & $299,4 \mathrm{a}$ & $250,5 \mathrm{~b}$ & $524,7 \mathrm{~b}$ & $373,1 \mathrm{~b}$ \\
\hline Diferença & $-8,2$ & 59,3 & 219,4 & 50,5 & 3,8 & 53,9 & 20,4 & 51,0 & 90,4 & 76,9 \\
\hline & & & & & \multicolumn{7}{c}{ Horizonte B } & & & & \\
DQM+S & $415,6 \mathrm{a}$ & $492,9 \mathrm{a}$ & $740,1 \mathrm{a}$ & $838,8 \mathrm{a}$ & $366,2 \mathrm{a}$ & $456,6 \mathrm{a}$ & $531,1 \mathrm{a}$ & $508,1 \mathrm{a}$ & $545,2 \mathrm{a}$ & $396,6 \mathrm{a}$ \\
DQM & $383,1 \mathrm{~b}$ & $448,2 \mathrm{~b}$ & $654,3 \mathrm{~b}$ & $728,7 \mathrm{~b}$ & $375,6 \mathrm{a}$ & $401,3 \mathrm{~b}$ & $499,5 \mathrm{~b}$ & $487,2 \mathrm{a}$ & $475,4 \mathrm{~b}$ & $346,0 \mathrm{~b}$ \\
\hline Diferença & 32,5 & 44,7 & 85,8 & 110,1 & $-9,4$ & 55,3 & 31,6 & 20,9 & 69,8 & 50,6 \\
\hline
\end{tabular}

(1)LAx: Latossolo Amarelo coeso; LVAd: Latossolo Vermelho-Amarelo distrófico; LVd: Latossolo Vermelho distrófico; LVdf: Latossolo Vermelho distroférrico; PAd: Argissolo Amarelo distrófico; PVAd: Argissolo Vermelho-Amarelo distrófico; PVd: Argissolo Vermelho distrófico; NVd: Nitossolo Vermelho distrófico; CXbd1: Cambissolo Háplico Tb distrófico originado de filito; CXbd2: Cambissolo Háplico Tb distrófico originado de gnaisse; médias seguidas de mesma letra nas colunas, dentro de cada solo, não diferem entre si a $1 \%$ de probabilidade pelo teste de Tukey. 
Os Cambissolos apresentaram reflexos intensos de caulinita (Figuras 3 e 4), chegando a ser maiores que os de quartzo no caso do CXbd1 (Figura 3), os quais se mantiveram após a sonificação do pseudosilte. Isso provavelmente está associado ao fato de esses solos terem se desenvolvido sobre um material pré-intemperizado, conforme relatos de Resende et al. (1988) de que alguns Cambissolos podem re-

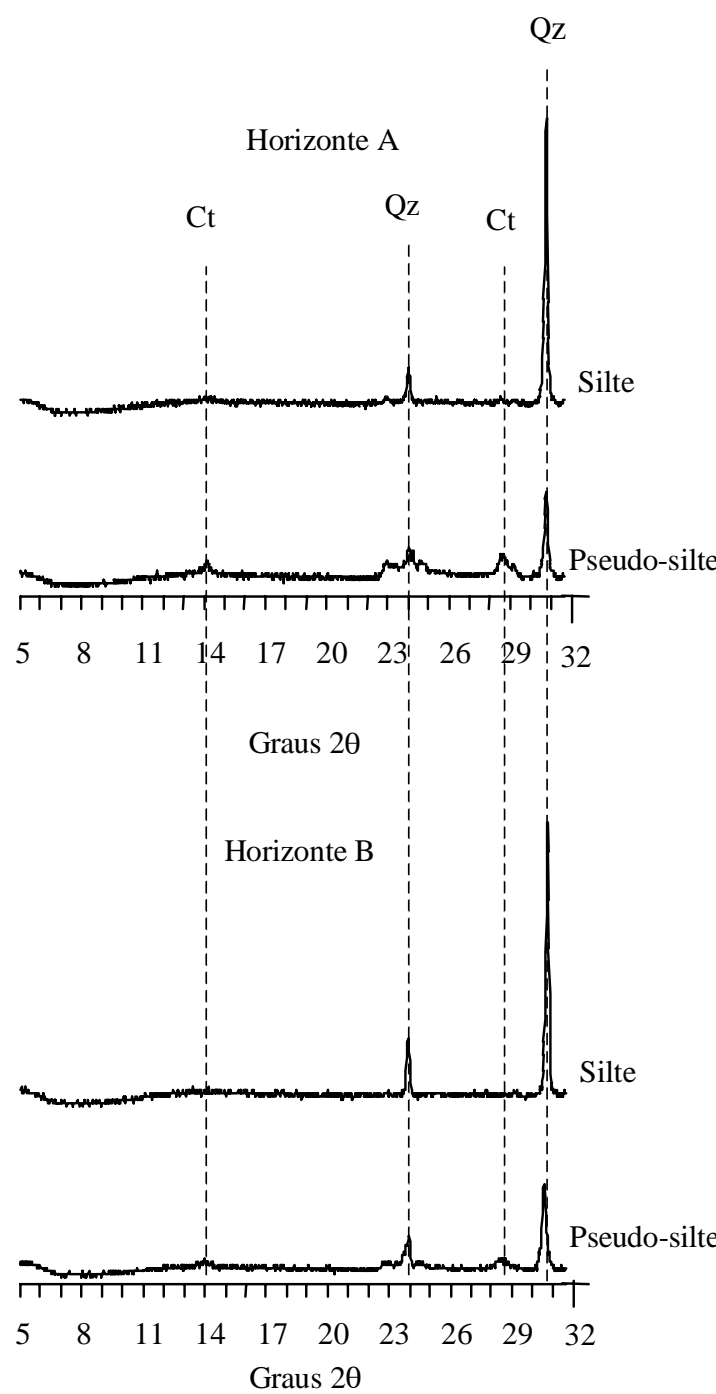

Figura 1. Difratogramas de raios- $X$ das frações silte e pseudo-silte dos horizontes A e B do Latossolo Amarelo coeso (Lax). Ct: caulinita; Qz: quartzo. sultar da remoção acentuada de material de antigos Latossolos, formados a partir do horizonte C subjacente ao Latossolo propriamente dito. Nesse caso, o Cambissolo atual não possui minerais facilmente intemperizáveis. Mineralogicamente é como se fosse um Latossolo, só que com maior teor de silte, no qual, freqüentemente, encontra-se o mesmo mineral que domina a fração argila, a caulinita.

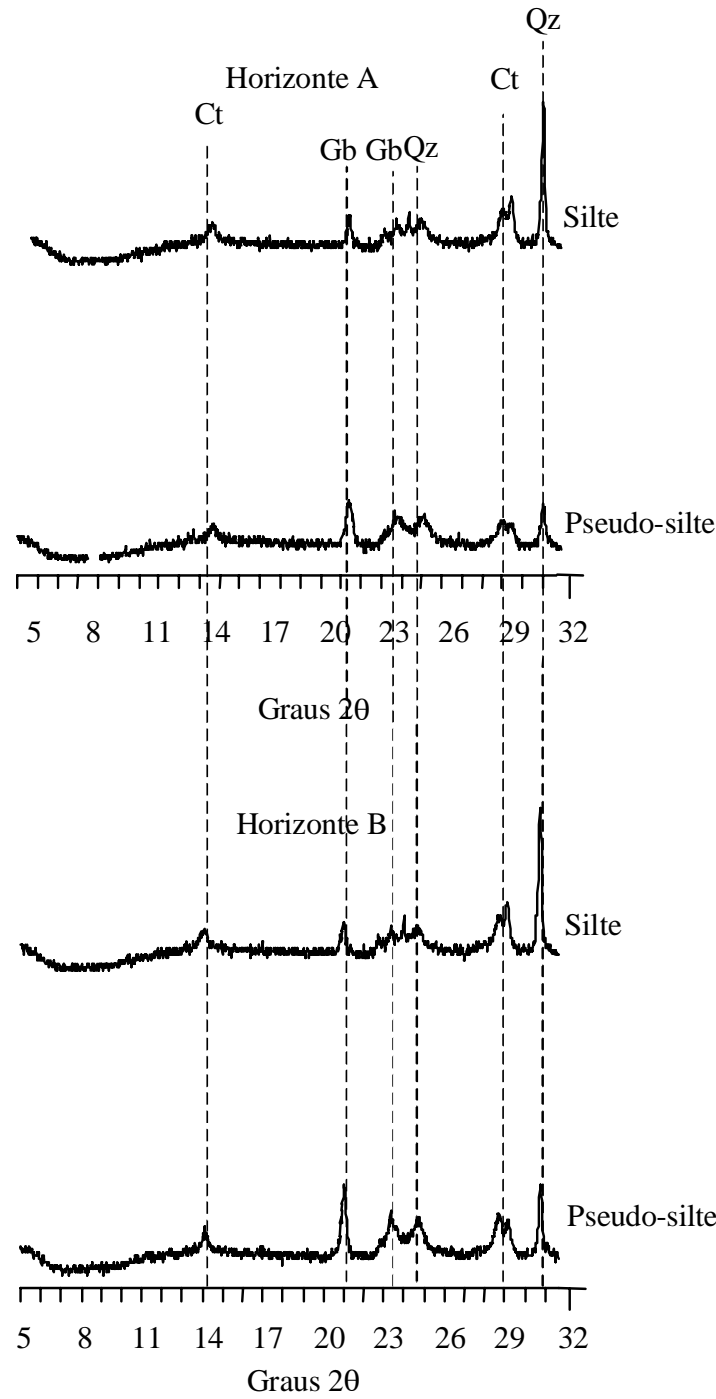

Figura 2. Difratogramas de raios- $X$ das frações silte e pseudo-silte dos horizontes A e B do Latossolo Vermelho distrófico (LVd). Ct: caulinita; Gb: gibbsita; Qz: quartzo. 
O intenso reflexo de caulinita na fração silte dos Cambissolos pode estar relacionado também com a presença de pseudomorfos de caulinita do tamanho de silte (Pinto, 1971). Uma vez que esses solos se desenvolveram a partir do horizonte $\mathrm{C}$ de antigos Latossolos, estando, portanto, mais próximos da rocha de origem, os pseudomorfos de caulinita, comuns no horizonte $\mathrm{Cr}$ de muitos solos, quebram-se em direção à superfície (Resende et al., 1997), aumentando sua superfície específica.

Ocorreu, entretanto, uma destruição de microagregados presentes na fração pseudo-silte desses solos, representado pelos menores teores de gibbsita e, principalmente, de caulinita na fração silte em relação ao pseudo-silte e na fração argila desagregada (Tabela 2).

Nos solos LVd e LVdf, independentemente dos horizontes considerados, os teores de gibbsita na fração silte foram superiores aos encontrados nos demais solos (Tabela 2 ) e estão relacionados, além da possibilidade da presença de pseudomorfos de gibbsita no tamanho de silte (Jolicoeur et al., 2000), à maior dificuldade de se destruir os microagregados presentes nesses solos. Silva et al. (1998) e Ferreira

Tabela 2. Teores de gibbsita (Gb) e caulinita (Ct) e relação $\mathrm{Gb} /(\mathrm{Gb}+\mathrm{Ct})$ em amostras desferrificadas das frações pseudo-silte, silte e argila desagregada, nos horizontes A e B dos diferentes solos em estudo.

\begin{tabular}{|c|c|c|c|c|c|c|c|c|c|}
\hline \multirow[t]{3}{*}{ Horizontes } & \multicolumn{3}{|c|}{ Pseudo-silte } & \multicolumn{3}{|c|}{ Silte } & \multicolumn{3}{|c|}{ Argila desagregada } \\
\hline & $\mathrm{Gb}$ & $\mathrm{Ct}$ & $\mathrm{Gb} /(\mathrm{Gb}+\mathrm{Ct})$ & $\mathrm{Gb}$ & $\mathrm{Ct}$ & $\mathrm{Gb} /(\mathrm{Gb}+\mathrm{Ct})$ & \multirow{2}{*}{\multicolumn{2}{|c|}{---- $\left(\mathrm{g} \mathrm{kg}^{-1}\right)$------ }} & \multirow[t]{2}{*}{$\mathrm{Gb} /(\mathrm{Gb}+\mathrm{Ct})$} \\
\hline & \multicolumn{3}{|c|}{---- $\left(\mathrm{g} \mathrm{kg}^{-1}\right)$----- } & \multicolumn{3}{|c|}{---- $\left(\mathrm{g} \mathrm{kg}^{-1}\right)$----- } & & & \\
\hline & & & & \multicolumn{3}{|c|}{ Latossolo Amarelo coeso } & & & \\
\hline A & 17,63 & 260,37 & 0,06 & 1,60 & 14,49 & 0,10 & 5,58 & 529,87 & 0,01 \\
\hline \multirow[t]{2}{*}{ B } & 12,15 & 276,72 & 0,04 & 1,20 & 14,80 & 0,07 & 1,12 & 690,50 & 0,00 \\
\hline & \multicolumn{9}{|c|}{ Latossolo Vermelho-Amarelo distrófico } \\
\hline A & 152,28 & 240,65 & 0,39 & 5,75 & 18,81 & 0,23 & 220,64 & 402,43 & 0,35 \\
\hline \multirow[t]{2}{*}{ B } & 110,99 & 369,45 & 0,23 & 4,94 & 39,03 & 0,11 & 309,25 & 527,13 & 0,37 \\
\hline & \multicolumn{9}{|c|}{ Latossolo Vermelho distrófico } \\
\hline A & 256,73 & 167,98 & 0,60 & 11,98 & 15,13 & 0,44 & 421,16 & 171,73 & 0,71 \\
\hline \multirow[t]{2}{*}{$\mathrm{B}$} & 354,14 & 212,49 & 0,62 & 12,32 & 18,87 & 0,39 & 651,96 & 293,42 & 0,69 \\
\hline & \multicolumn{9}{|c|}{ Latossolo Vermelho distroférrico } \\
\hline A & 240,03 & 229,63 & 0,51 & 20,98 & 16,55 & 0,56 & 338,68 & 338,42 & 0,50 \\
\hline \multirow[t]{2}{*}{ B } & 281,27 & 244,89 & 0,53 & 15,24 & 19,95 & 0,43 & 454,40 & 437,42 & 0,51 \\
\hline & \multicolumn{9}{|c|}{ Argissolo Amarelo distrófico } \\
\hline A & 7,08 & 316,61 & 0,02 & 1,30 & 14,77 & 0,08 & 5,98 & 513,24 & 0,01 \\
\hline \multirow[t]{2}{*}{ B } & 5,24 & 623,25 & 0,01 & 0,82 & 15,74 & 0,05 & 7,75 & 665,45 & 0,01 \\
\hline & \multicolumn{9}{|c|}{ Argissolo Vermelho-Amarelo distrófico } \\
\hline A & 52,69 & 345,98 & 0,13 & 2,19 & 18,59 & 0,11 & 95,36 & 398,69 & 0,19 \\
\hline \multirow[t]{2}{*}{ B } & 53,69 & 485,52 & 0,10 & 1,07 & 20,26 & 0,05 & 110,29 & 512,01 & 0,18 \\
\hline & \multicolumn{9}{|c|}{ Argissolo Vermelho distrófico } \\
\hline A & 46,02 & 324,17 & 0,12 & 3,71 & 18,40 & 0,17 & 107,71 & 351,02 & 0,23 \\
\hline \multirow[t]{2}{*}{$\mathrm{B}$} & 59,01 & 286,37 & 0,17 & 2,19 & 20,54 & 0,10 & 229,72 & 449,30 & 0,34 \\
\hline & \multicolumn{9}{|c|}{ Nitossolo Vermelho distrófico } \\
\hline A & 69,15 & 180,66 & 0,28 & 2,50 & 14,46 & 0,15 & 156,10 & 333,96 & 0,32 \\
\hline \multirow[t]{2}{*}{ B } & 139,82 & 248,35 & 0,36 & 1,45 & 15,84 & 0,08 & 274,77 & 339,36 & 0,45 \\
\hline & \multicolumn{9}{|c|}{ Cambissolo Háplico Tb distrófico originado de filito } \\
\hline A & 8,30 & 208,77 & 0,25 & 2,15 & 18,47 & 0,10 & 135,26 & 339,79 & 0,28 \\
\hline \multirow[t]{2}{*}{ B } & 80,22 & 330,86 & 0,20 & 1,87 & 18,69 & 0,09 & 121,24 & 282,62 & 0,30 \\
\hline & \multicolumn{9}{|c|}{ Cambissolo Háplico Tb distrófico originado de gnaisse } \\
\hline A & 45,01 & 260,09 & 0,15 & 2,66 & 25,94 & 0,09 & 113,19 & 300,69 & 0,27 \\
\hline $\mathrm{B}$ & 53,36 & 417,62 & 0,11 & 2,12 & 44,90 & 0,05 & 110,72 & 405,02 & 0,21 \\
\hline
\end{tabular}


et al. (1999a) também consideram a gibbsita como o principal agente de agregação de Latossolos.

Para analisar as possíveis causas da dificuldade de dispersão da argila dos solos, foram realizadas correlações entre os teores de pseudo-silte (PS), silte (S) e argila desagregada (AD) com alguns atri-
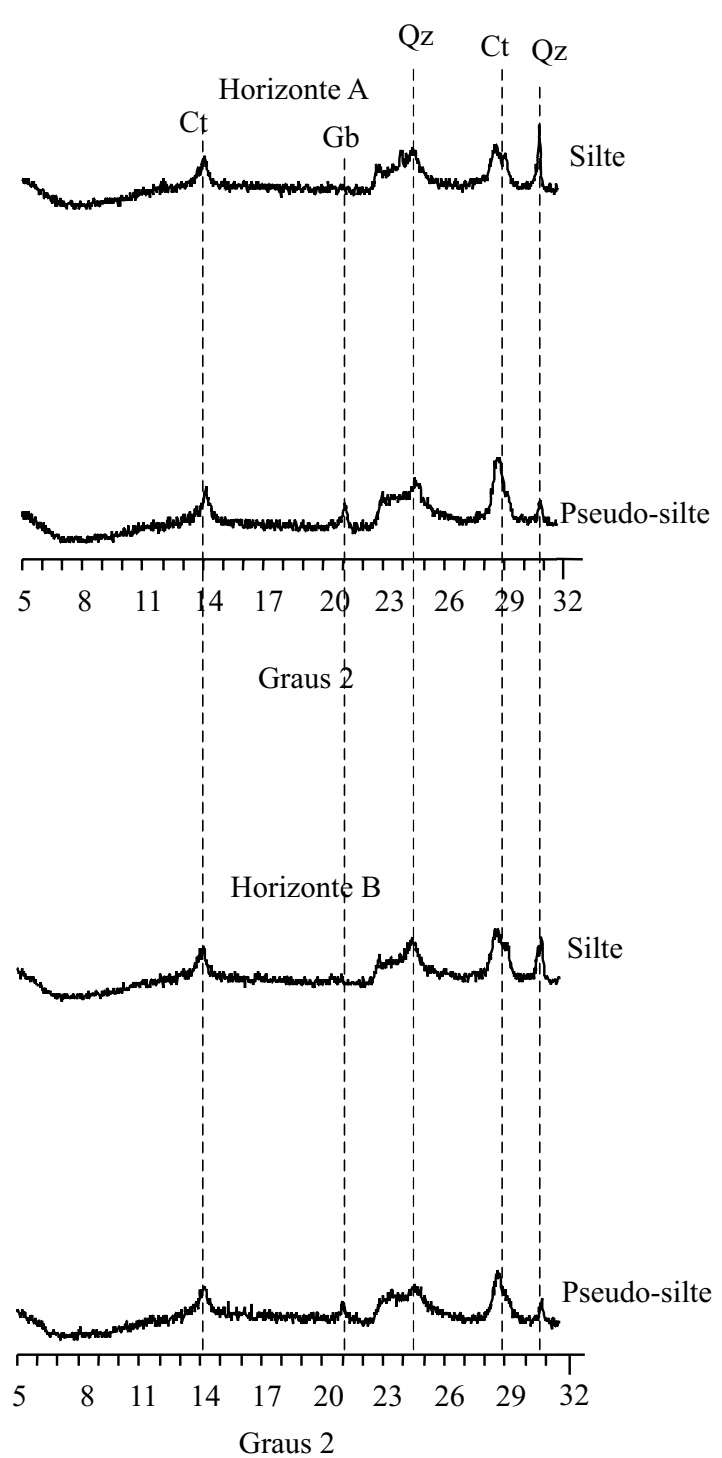

Figura 3. Difratogramas de raios- $X$ das frações silte e pseudo-silte dos horizontes A e B do Cambissolo Háplico argila de atividade baixa distrófico 1 (CXbd1). Ct: caulinita; Gb: gibbsita; Qz: quartzo. butos químicos e mineralógicos determinados nessas frações (Tabela 3).

Os teores de PS se correlacionaram diretamente e de forma significativa apenas com os teores de gibbsita, relação $\mathrm{Gb} /(\mathrm{Gb}+\mathrm{Ct}), \mathrm{Al}_{\mathrm{d}}, \mathrm{Al}_{\mathrm{o}}$ e $\mathrm{Al}_{\mathrm{p}}$ dessa fração. Quanto a S, essa correlação ocorreu apenas com

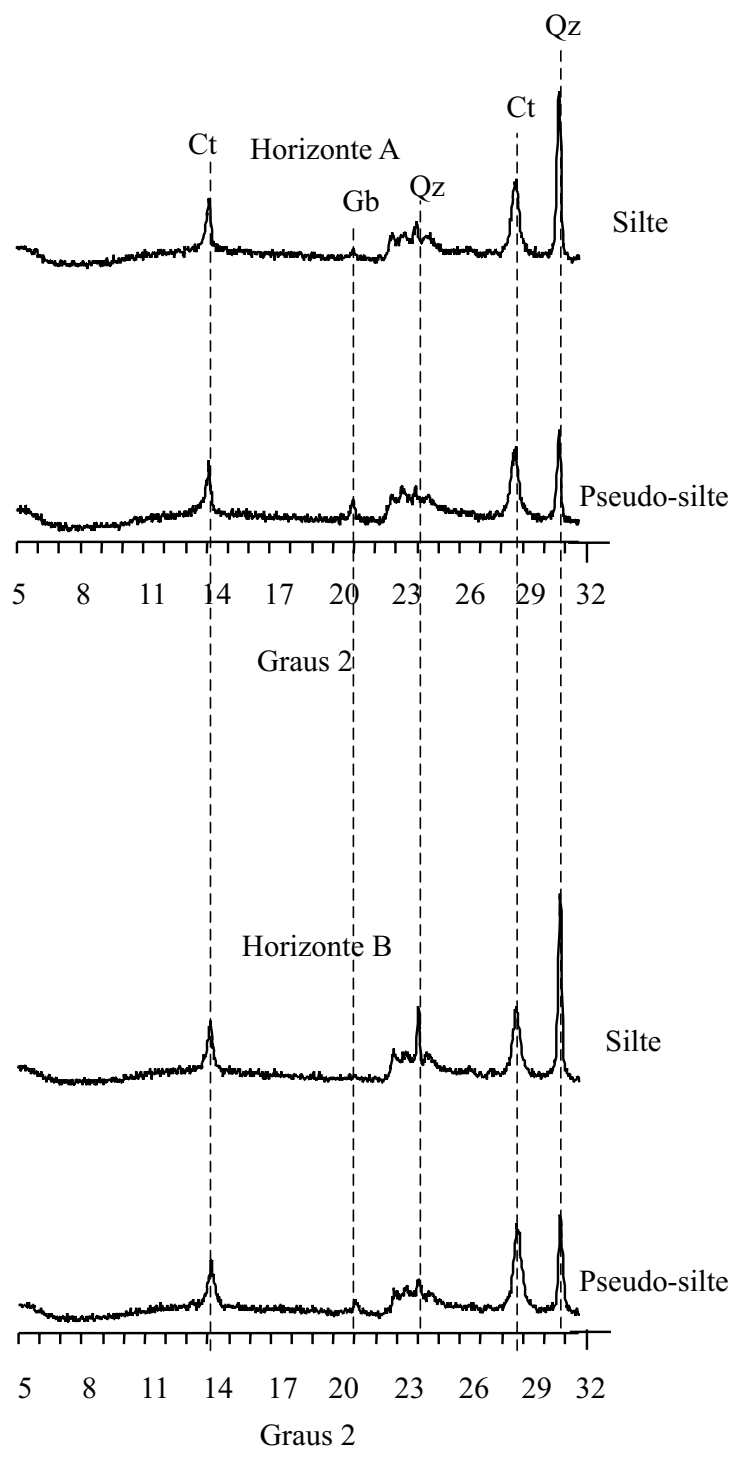

Figura 4. Difratogramas de raios- $X$ das frações silte e pseudo-silte dos horizontes A e B do Cambissolo Háplico argila de atividade baixa distrófico 2 (CXbd2). Ct: caulinita; Gb: gibbsita; Qz: quartzo. 
o $\mathrm{Al}_{\mathrm{d}}$; quanto a $\mathrm{AD}$, apenas com $\mathrm{Gb}$, relação $\mathrm{Gb} /(\mathrm{Gb}+\mathrm{Ct})$. O teor de caulinita correlacionou-se de forma inversa com os teores de PS e AD, mas de forma significativa apenas com a fração AD.

A correlação direta com teores de gibbsita e inversa com teores de caulinita reflete a importância desses constituintes na formação e estabilização de agregados do tamanho de silte, corroborando com Ferreira et al. (1999a) e Pedrotti (2000), que concluíram serem esses os constituintes mineralógicos que maior influência exercem sobre as propriedades associadas à estrutura do solo. Assim, solos mais cauliníticos devem apresentar estrutura menos resistente ao rompimento pela agitação mecânica, sendo mais fáceis de serem dispersos pelo método tradicional de agitação, ao passo que solos mais gibbsíticos devem ser mais difíceis de serem dispersos. Tais resultados são concordantes com os apresentados por Netto (1996).

A análise dos resultados das correlações que envolveram as formas de alumínio $\left(\mathrm{Al}_{\mathrm{d}}\right.$ e $\left.\mathrm{Al}_{\mathrm{o}}\right)$ na fração pseudo-silte também indica que quanto maior o conteúdo desses componentes maior a quantidade de argila que permanece não dispersa pelo método de agitação rápida, na forma como considerada no presente trabalho. Esses resultados demonstram a importância do $\mathrm{Al}$ na resistência à desagregação e, por conseguinte, nas propriedades relacionadas com a estabilidade desses agregados, corroborando com Deshpande et al. (1968), Goldberg et al. (1990), Ferreira et al. (1999a) e Pedrotti (2000), os quais destacam o importante papel dos óxidos, tanto os cristalinos como os pouco cristalinos, na estabilização de agregados do solo, por gerarem dificuldades de dispersão. Nenhuma explicação foi encontrada para justificar a correlação com o $\mathrm{Al}_{\mathrm{d}}$ da fração silte, pois não seria esperado que nesta fração fossem encontrados residualmente componentes que pudessem conferir resistência à dispersão.

Os valores de $\mathrm{Al}_{\mathrm{p}}$, que representam o $\mathrm{Al}$ ligado à matéria orgânica, correlacionaram-se de forma direta e significativa com os teores de PS, confirmando os resultados obtidos por Pedrotti (2000), que também discute a relação entre as formas de $\mathrm{Al}$ associadas à matéria orgânica com atributos físicos relacionados à agregação dos solos. Segundo Tisdall \& Oades (1982), a matéria orgânica atua na estabilização e formação de agregados, pois polímeros orgânicos ligam-se às partículas inorgânicas através de cátions polivalentes e polímeros hidroximetálicos.

Embora estudos como os de Schwertmann (1988), Goldberg et al. (1990), Colombo \& Torrent (1991) e Pinheiro-Dick \& Schwertmann (1996) apontem para uma influência dos óxidos de Fe na agregação do solo, as diversas formas de Fe determinadas nas diferentes frações consideradas no presente trabalho, o qual englobou solos com teores de $\mathrm{Fe}$ do ataque sulfúrico desde baixos $\left(25,1 \mathrm{~g} \mathrm{~kg}^{-1}\right.$ horizonte $\mathrm{A}$ do PA) até altos (237,7 $\mathrm{g} \mathrm{kg}^{-1}$ para o horizonte B do LVdf), não apresentaram correlação com os teores de PS, S ou AD, concordando com Deshpande et al. (1968) e Ferreira et al. (1999a), que observaram participação discreta dos óxidos de Fe na agregação. Lima \& Anderson (1997) também sugerem pouca relação entre as concentrações de óxidos de Fe e tamanho de agregados, ao menos para agregados do tamanho de silte e areia.

Tabela 3. Coeficientes de correlação obtidos das análises de regressão linear relacionando os teores de pseudo-silte (PS), silte (S) e argila desagregada (AD) com alguns atributos químicos e mineralógicos dos solos estudados ${ }^{(1)}$.

\begin{tabular}{lccccccccc}
\hline Fração & $\mathrm{Gb}$ & $\mathrm{Ct}$ & $\mathrm{Gb} /(\mathrm{Gb}+\mathrm{Ct})$ & $\mathrm{Al}_{\mathrm{d}}$ & $\mathrm{Al}_{\mathrm{o}}$ & $\mathrm{Al}_{\mathrm{p}}$ & $\mathrm{Fe}_{\mathrm{d}}$ & $\mathrm{Fe}_{\mathrm{o}}$ & $\mathrm{Fe}_{\mathrm{p}}$ \\
\hline $\mathrm{PS}$ & $0,629^{*}$ & $-0,474^{\mathrm{ns}}$ & $0,694^{* *}$ & $0,650^{* *}$ & $0,716^{* *}$ & $0,598^{*}$ & $0,478^{\mathrm{ns}}$ & $0,161^{\mathrm{ns}}$ & $0,409^{\mathrm{ns}}$ \\
$\mathrm{S}$ & $0,503^{\mathrm{ns}}$ & $0,018^{\mathrm{ns}}$ & $0,477^{\mathrm{ns}}$ & $0,676^{* *}$ & $0,439^{\mathrm{ns}}$ & $0,230^{\mathrm{ns}}$ & $0,543^{\mathrm{ns}}$ & $0,003^{\mathrm{ns}}$ & $0,141^{\mathrm{ns}}$ \\
$\mathrm{AD}$ & $0,595^{*}$ & $-0,658^{* *}$ & $0,732^{* *}$ & $0,514^{\mathrm{ns}}$ & $0,505^{\mathrm{ns}}$ & $0,329^{\text {ns }}$ & $0,460^{\mathrm{ns}}$ & $0,017^{\mathrm{ns}}$ & $0,205^{\text {ns }}$ \\
\hline
\end{tabular}

${ }^{(1)} \mathrm{Gb}$ : gibbsita; $\mathrm{Ct}$ : caulinita; $\mathrm{Al}_{\mathrm{d}}$ : alumínio extraído pelo ditionito-citrato-bicarbonato; $\mathrm{Al}_{\mathrm{o}}$ : alumíno extraído pelo oxalato ácido de amônio; $\mathrm{Al}_{\mathrm{p}}$ : alumínio extraído pelo pirofosfato de sódio; $\mathrm{Fe}_{\mathrm{d}}$ : ferro extraído pelo ditionito-citrato-bicarbonato; $\mathrm{Fe}_{\mathrm{o}}$ : ferro extraído pelo oxalato ácido de amônio; $\mathrm{Fe}_{\mathrm{p}}$ : ferro extraído pelo pirofosfato de sódio. ${ }^{\text {ns }}$ ão-significativo. $*$ e **Significativo a $5 \%$ e a $1 \%$ de probabilidade pelo teste $\mathrm{t}$, respectivamente. 


\section{Conclusões}

1. As composições mineralógica e química dos solos têm efeito marcante na dispersão da argila, com reflexos na fração silte.

2. Maiores teores de gibbsita refletem em maior estabilidade dos agregados do tamanho de silte, mas o aumento da caulinita proporciona efeito inverso.

3. As formas de $\mathrm{Al}$ determinadas na fração pseudosilte estão associadas à maior dificuldade de dispersão da fração argila dos solos.

\section{Referências}

COLOMBO, C.; TORRENT, J. Relationships between aggregation and iron oxides in Terra Rosa soils from Southern Italy. Catena, Amsterdam, v. 18, n. 1, p. 51-59, Feb. 1991.

DESHPANDE, T. L.; GREENLAND, D. J.; QUIRK, J. P. Charges in soil properties associated with the removal of iron and aluminum oxides. Journal of Soil Science, Oxford, v. 19, n. 1, p. 108-122, Mar. 1968.

DONAGEMMA, G. K. Pré-tratamento na análise textural visando a minimização do pseudo-silte em Latossolos de Minas Gerais. 2000. 89 f. Dissertação (Mestrado em Solos e Nutrição de Plantas) - Universidade Federal de Viçosa, Viçosa, MG, 2000.

EDWARDS, A. P.; BREMNER, J. M. Dispersion of soil particles by sonic vibration. Journal of Soil Science, Oxford, v. 18, n. 1, p. 47-63, Mar. 1967.

EMBRAPA. Centro Nacional de Pesquisa de Solos (Rio de Janeiro, RJ). Manual de métodos de análise de solo. 2. ed. rev. atual. Rio de Janeiro, 1997. 212 p.

FERREIRA, M. M.; FERNANDES, B.; CURI, N. Influência da mineralogia da fração argila nas propriedades físicas de latossolos da região Sudeste do Brasil. Revista Brasileira de Ciência do Solo, Viçosa, MG, v. 23, n. 3, p. 515-524, jul./set. 1999a.

FERREIRA, M. M.; FERNANDES, B.; CURI, N. Mineralogia da fração argila e estrutura de latossolos da região sudeste do Brasil. Revista Brasileira de Ciência do Solo, Viçosa, MG, v. 23, n. 3, p. 507-514, jul./set. 1999b.

GENRICH, D. A.; BREMNER, J. M. A reevaluation of the ultrasonic vibration method of dispersing soils. Soil Science Society of America Proceedings, Madison, v. 36, n. 6, p. 944-947, Nov./Dec. 1972.
GOLDBERG, S.; KAPOOR, B. S.; RHOADES, J. D. Effect of aluminum and iron oxides and organic matter on flocculation and dispersion of arid zone soils. Soil Science, Baltimore, v. 150, n. 3, p. 587-593, Sept. 1990.

GREGORICH, E. G.; KACHANOSKI, R. G.; VORONEY, R. P. Ultrasonic dispersion of aggregates: distribution of organic matter in size fractions. Canadian Journal of Soil Science, Ottawa, v. 68, n. 2, p. 395-403, May 1988.

JOLICOEUR, S.; ILDEFONSE, P.; BOUCHARD, M. Kaolinite and gibbsite weathering of biotite within saprolites and soil of central Virginia. Soil Science Society of America Journal, Madison, v. 64, n. 3, p. 1118-1129, May/June 2000

KUNZE, G. W.; DIXON, J. B. Pretreatments for mineralogical analysis. In: KLUTE, A. (Ed.). Method of soil analysis: physical and mineralogical methods. 2. ed. Madison: American Society of Agronomy/Soil Science Society of America, 1986. Part 1, p. 91-99. (Agronomy, 5).

LIMA, J. M.; ANDERSON, S. J. Aggregation and aggregate size effects on extractable iron and aluminium in two Hapludoxs. Soil Science Society of America Journal, Madison, v. 61, n. 5, p. 965-970, Sept./Oct. 1997.

McKEAGUE, J. A. An evaluation of $0,1 \mathrm{M}$ pyrophosphate and pyrophosphate-dithionite in comparison with oxalate as extractants of the accumulation products in Podzols and some others soils. Canadian Journal of Soil Science, Ottawa, v. 47, p. 95-99, 1967.

MEHRA, O. P.; JACKSON, M. L. Iron oxide removal from soils and clays by a dithionite-citrate system buffered with sodium bicarbonate. Clays and Clay Minerals, Ottawa, v. 3, p. 317-327, 1960

MOURA FILHO, W.; BUOL, S. W. Studies of a Latossol Roxo (Eutrustox) in Brazil: micromorphology effect on ion release. Experientiae, Viçosa, MG, v. 13, n. 7, p. 235 247, abr. 1972.

NETTO, A. R. Influência da mineralogia da fração argila sobre propriedades físico-químicas de solos brasileiros. 1996. 144 f. Dissertação (Mestrado em Solos e Nutrição de Plantas) - Universidade Federal de Viçosa, Viçosa, 1996.

PEDROTTI, A. Relação entre atributos físicos e alumínio no solo. 2000. 60 f. Tese (Doutorado em Solos e Nutrição de Plantas) - Universidade Federal de Lavras, Lavras, 2000. 
PINHEIRO-DICK, D.; SCHWERTMANN, U. Microaggregates from Oxisols and Inceptisols: dispersion through selective dissolution and physicochemical treatments. Geoderma, Amsterdam, v. 74, n. 1/2, p. 4963, Nov. 1996

PINTO, O. C. B. Formation of a kaolinite from a biotite feldspar gneiss in four strongly weathered soil profiles from Minas Gerais, Brazil. 1971. 133 leaves. M.Sc. (Dissertation in Agronomy) - Purdue University, West Lafayette, 1971.

RESENDE, M.; CURI, N.; DUARTE, M. N. Mineralogia, química e estratificação de ambientes. In: CONGRESSO BRASILEIRO DE CIÊNCIA DO SOLO, 26., 1997, Rio de Janeiro. Palestra... Rio de Janeiro: Sociedade Brasileira de Ciência do Solo, 1997. 25 p. CD-ROM. Seção 2.

RESENDE, M.; CURI, N.; LANI, J. L. Tropical soils: implications on sustainable development. In: SCIENCE for sustainable development in Latin America and the Caribbean. Rio de Janeiro: Academia Brasileira de Ciências, 1999. Não paginado.

RESENDE, M.; CURI, N.; SANTANA, D. P. Pedologia e fertilidade do solo: interações e aplicações. Brasília: MEC/Esal/Potafos, 1988. 81 p.

SÁ, M. A. C. de; LIMA, J. M.; LAGE, G. Procedimentopadrão para medida da potência liberada pelo aparelho de ultra-som. Ciência e Agrotecnologia, Lavras, v. 24, n. 1, p. 300-306, jan./mar. 2000.
SALY, R. Use of ultrasonic vibration for dispersion soil samples. Soviet Soil Science, Silver Spring, v. 11, p. $1547-1559,1967$.

SANTANA, D. P. Estudo de solos do Triângulo Mineiro e de Viçosa: I. mineralogia: II. adsorção de fosfatos. 1973. 56 f. Dissertação (Mestrado em Solos e Nutrição de Plantas) - Universidade Federal de Viçosa, Viçosa, MG, 1973.

SCHWERTMANN, U. Some properties of soil and synthetic iron oxides. In: STUCKI, J. W.; GOODMAN, B. A.; SCHWERTMANN, U. (Ed.). Iron in (ours) soils and clay minerals. Dordrecht: Reidel, 1988. p. 203-250.

SCHWERTMANN, U. The differentiation of iron oxides in soils by a photochemical extraction with acid ammonium oxalate. Zeitschrift fuer Pflanzenernaehrung und Bodenkunde, Weinheim, v. 105, p. 194-201, 1964.

SILVA, M. L. N.; BLANCANEAUX, P.; CURI, N.; LIMA, J. M.; MARQUES, J. J. G. S. M.; CARVALHO, A. M. Estabilidade de agregados de Latossolo VermelhoEscuro cultivado com sucessão milho-adubo verde. Pesquisa Agropecuária Brasileira, Brasília, v. 33, n. 1, p. $97-$ 103, jan. 1998.

TISDALL, J. M.; OADES, J. M. Organic matter and water-stable aggregates in soils. Journal of Soil Science, Oxford, v. 33, n. 2, p. 141-163, June 1982.

VITORINO, A. C. T.; FERREIRA, M. M.; OLIVEIRA, G. C.; DIAS JÚNIOR, M. S.; SÁ, M. A. C. de; LIMA, J. M.; CURI, N. Níveis de energia ultra-sônica na dispersão de argila de solos da região de Lavras (MG). Ciência e Agrotecnologia, Lavras, v. 25, n. 6, p. 1330-1336, nov./ dez. 2001. 